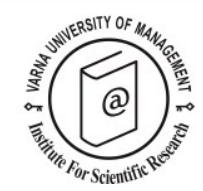

\title{
The impact of life events on the tourism behaviour of senior citizens in Freising, Germany
}

\author{
Dominik Huber $^{1}$
}

Received: 16/04/2015

1101 St. Herliers Bay Road, St. Herliers 1071, Auckland, New Zealand; te: 0064221861600 ; e-mail: dominik_huber@hotmail.de

Supervisors: Prof. Simon Milne

Associate Prof. Ken Hyde

Institution awarding the Ph. D. Degree: Auckland University of Technology

Date of defence: 20/11/2014

(c) 2015 Varna University of Management. All rights reserved

Citation: Huber, D. (2015) The impact of life events on the tourism behaviour of senior citizens in Freising, Germany. Doctoral Dissertation Summary. European Journal of Tourism Research 11, pp. 194-198

\section{Goal and objectives of the dissertation Goal}

To gain a better understanding of seniors' tourism behaviour and to uncover the meanings behind travelling in later years.

\section{Objectives}

- to gain a comprehensive understanding of the impact of life events on seniors' tourism behaviour

- to understand the development of travel behaviour over the life course

- to discover variances in senior travel behaviour caused by identifiable life events

- to understand why seniors cease travelling

- to contribute to the methodological body of knowledge by applying qualitative biographic research methods to investigate seniors' tourism behaviour

- to contribute to academic theory by applying an interdisciplinary approach of 194 tourism social sciences, gerontology and human development

- to contribute to academic theory by merging tourism constraint and facilitator models with an ecological perspective

\section{Methodology}

Existing research on seniors' tourism behaviour largely focuses on quantitative measures and does not reflect the diverse nature of seniors. For this reason a real-life event approach was applied to investigate seniors' tourism behaviour in depth.

The research paradigm adopted in this thesis followed a critical realist and pragmatist ontology which is informed by a post-positivist research philosophy. The research draws on a multiple case study and was conducted between October 2011 and September 2012 with 23 seniors aged 60 years and older living 
in Freising, Germany. This thesis combined two sets of semi-structured face-to-face indepth biographic interviews in order to improve and validate the retrieved data from the first interview phase. The analytical framework includes the identification of travel periods, a within-case and a cross-case thematic analysis.

\section{Results}

The thesis identified a number of live events and life-event-related factors which can affect the tourism behaviour of seniors including: deteriorating health, age-psychological factors, detachment from children, pets as family members, migration and visiting friends and family, the living environment, grandparenthood, illness of the spouse and nursing obligations, the loss of the spouse, meeting a new partner, working commitments and retirement, and inheritance.

Findings of the study showed that the impact of life events on the tourism behaviour of seniors is diverse and dependent on conditions and living circumstances. Travel distances and durations and tourism activities for example can increase decrease or stagnate. Similarly, motivations are manifold and seniors travel for a variety of reasons such as seeking experiences, socialization, relaxation or having a last meaningful travel experience.

The thesis found that tourism plays a significant role in successful aging strategies and can contribute to life satisfaction and individual well-being in old age. Minor evidence was found that could support theories of disengagement. Only those who found themselves socially isolated showed signs of active disengagement from society. These seniors, who had been socially isolated by unfortunate circumstances, simultaneously experienced other constraints and largely ceased their tourism participation.

\section{Theoretical conclusions}

This thesis suggests that seniors' tourism behaviour can be explained by ecological constraints and facilitators and translated Crawford et al.'s (1991) and Jackson's (2005) hierarchical leisure constraints model into the senior tourism context. The generated advanced constraints and facilitators model of senior tourism behaviour based on a number of propositions regarding properties of life events and their relationships to other concurring factors. The structure of the model conforms to Crawford, Jackson, and Godbey's (1991) original leisure constraints concept in many aspects. Tourism behaviour is formed by travel preferences which are constrained and negotiated on intrapersonal, interpersonal and structural levels. Results also suggest a certain hierarchy of constraints with the social nature of tourism holding a paramount position. Structural constraints are less powerful in prohibiting tourism participation but give travel behaviour a shape through the allocation of opportunities.

The newly developed model presented in this thesis adds Raymore's (2002) facilitators category and encompasses dimensions of the individual ecological system. This results in a distinction between intrapersonal and intrastructural, and microstructural and macrostructural constraints and facilitators. The difference between intrapersonal and intrastructural constraints is in how far physical conditions are internalised and perceived as a constraining factor. Because the thesis is focused on tourism, the model incorporates also a destination dimension which is subject to constraining or facilitating influences.

\section{Practical application of the dissertation}

Senior tourism is still an underdeveloped market. For the tourism industry it is crucial to gain a deeper understanding of the tourism behaviour of seniors in order to develop custom-tailored tourism products for this growing market segment. Results of the thesis show that the cease of travelling is associated with age related constraining factors and a lack of appropriate tourism products rather than with a loose of interest in tourism participation itself.

There is market potential for tourism businesses to develop and provide tourism products that help to overcome constraints to 
The impact of life events on the tourism behaviour of senior citizens in Freising, Germany. Doctoral Dissertation Summary.

travel participation and tourism activities. The thesis suggests that the whole service chain of tourism products needs to comply with senior friendly tourism components including the travel planning, transportation and services, products and infrastructure at the destination level. In particular carrying of luggage was identified as a constraining factor in later age.

Further practical applications of the thesis relate to the social nature of travelling since it is not only health which restricts tourism participation but also a deteriorating social environment. A popular approach to social participation of seniors is joining in clubs or associations. These are places where new travel groups are formed and travel decisions are shaped. Similar may account for emerging social networks where seniors can share and exchange tourism experiences. For the tourism industry it is important to understand how and where tourism decisions are made in order to place and advertise appropriate products effectively.

\section{Content of the dissertation}

\section{Abstract of chapter one}

The senior tourism market is a driving force of the tourism industry; for example predictions of the German market suggest that this segment will grow within the next few decades due to demographic and behavioural changes (Lohmann \& Aderhold, 2009). Little is known about the meanings behind the phenomenon of senior tourism (Sedgley, Pritchard, \& Morgan, 2006) and studies often provide only a homogeneous picture of older adults without considering a broader context of seniors' living conditions.

\section{Abstract of chapter two}

The thesis reflects the diverse nature of the senior population by applying a life events approach and explores key life events as they relate to the tourism behaviour of seniors. The theoretical framework of the thesis builds on constraints and facilitators (Crawford et. al., 1991), ecological systems theory (Bronfenbrenner, 1994), developmental perspectives on aging (e.g. Levinson, 1986) and gerontological theories, for example the 'innovative theory on successful aging' (Nimrod \& Kleiber, 2007).

\section{Abstract of chapter three}

German seniors are relatively wealthy and once retired they have an abundance of discretionary time (Motel-Klingbeil et al., 2010). The gap between rich and poor becomes increasingly evident but elderly who have insufficient income or suffer from illness can rely on a relatively strong social security system.

The individual tourism histories of German seniors are shaped by a number of historical epochal events (Spode, 2013). In particularly World War I and II and the following phase of economic prosperity, as well as the separation and reunification of East and West Germany had a strong influence on the tourism behaviour of this age cohort. Travelling became an integral part of the German population.

\section{Abstract of chapter four}

Following a critical realist and pragmatic research paradigm, the study employs multiple methods to address the research questions, including biographical interviews, ecomaps, the use of holiday photos and travel diaries, and thematic timelines. The research design builds on two interview phases. The first interview set used a life-history guide in order to identify life events affecting the travel behaviour of seniors. The second set was informed by the first phase of data collection and followed in parts a participatory research approach in order to increase data accuracy and to investigate travel periods in greater detail. The data analysis involved a withincase and cross-case thematic analysis.

\section{Abstract of chapter five}

A within-case analysis was applied for a selection of seven cases in order to reconstruct the individual life courses of the participants (Fuchs-Heinritz, 2009). This analysis was descriptive in nature and resulted in a detailed picture of how life events impact on tourism behaviour across the life course and in particular in senior years. 


\section{Abstract of chapter six}

The objective of the cross-case analysis was to identify relevant patterns and categories by comparing the 23 cases and involved thematic analysis (Braun \& Clark, 2006) and the use of thematic timelines. This procedure resulted in a number of influential factors which determine the tourism behaviour of seniors. Dominant factors relate to health issues, financial opportunities, time availability, social commitments and role allocations.

\section{Abstract of chapter seven}

The thesis found that life events can have a significant influence on the tourism behaviour of seniors. The theoretical interpretation of life events revealed that they have specific properties for example regarding quality (e.g. life events can be isolated or systemic) or hierarchical relationships with other life events.

Literature suggests that constraints and facilitators arise from life events (Hutchinson \& Kleiber, 2005) and therefore seniors' tourism behaviour was interpreted in the light of a conceptual framework which builds on an ecological constraints and facilitators approach. This resulted in a model of senior tourism constraints and facilitators which explains the tourism behaviour of elderly from an intrapersonal, intrastructural, interpersonal and structural perspective.

\section{Abstract of chapter eight}

The objective of this thesis was to gain a better understanding of the relationships between life events and the tourism behaviour of seniors. The research draws on a participatory two-phased biographical qualitative research design and employed ecomaps as a data collection technique.

The thesis identified a number of key life events affecting the tourism behaviour in later life and explored how and why seniors' tourism behaviour changes relative to these events. This thesis provides a better understanding of constraints and facilitators in the tourism context and advances the psychological knowledge of seniors' tourism behaviour.

\section{References:}

Baltes, P. B. (1997). On the incomplete architecture of human ontogeny: Selection, optimization, and compensation as foundation of developmental theory. American Psychologist, 52(4), 366-380.

Braun, V., \& Clarke, V. (2006). Using thematic analysis in psychology. Qualitative Research in Psychology, 3(2), 77101.

Bronfenbrenner, U. (1986). Ecology of the family as a context for human development: Research perspectives. Developmental Psychology, 22(6), 723-742.

Crawford, D. W., Jackson, E. L., \& Godbey, G. (1991). A hierarchical model of leisure constraints. Leisure Sciences: An Interdisciplinary Journal, 13(4), 309-320.

Fleischer, A., \& Pizam, A. (2002). Tourism constraints among Israeli seniors. Annals of Tourism Research, 29(1), 106-123.

Hutchinson, S., \& Kleiber, D. A. (2005). Leisure, constraints, and negative life events: Paradox and possibilities. In E. Jackson (Ed.), Constraints to Leisure (pp. 137-150). State College, PA: Venture Publishing.

Jackson, E. L. (2005). Impacts of life transitions on leisure and constraints to leisure. In E. L. Jackson (Ed.), Constraints to Leisure (pp. 115-136). State College, PA: Venture Publishing.

Levinson, D. J. (1986). A conception of adult development. American Psychologist, 41(1), 3-13.

Lohmann, M., \& Aderhold, P. (2009). Urlaubsreisetrends 2020 - Die RA Trendstudie. Kiel, Germany.

Motel-Klingbeil, A., Wurm, S., \& TeschRoemer, C. (2010). Altern im Wandel. Befunde des Deutschen Alterssurveys (DEAS). Stuttgart, Germany. 
Nimrod, G., \& Kleiber, D. A. (2007). Reconsidering change and continuity in later life: Toward an innovation theory of successful aging. The International Journal of Aging and Human Development, 65(1), 1-22.

Sedgley, D., Pritchard, A., \& Morgan, N. (2006). Understanding older women's leisure: the value of biographical research methods. Tourism, 54(1), 43-51.
Spode, H. (2013). Zur Einfuehrung: Eine Geschichte des Verreisens. In S. D. H. Museum (Ed.), Rund um die Welt. Tourismusplakate aus der Sammlung des Deutschen Historischen Museums (pp. 6-11). Berlin, Germany: Stiftung Deutsches Historisches Museum. 